\title{
algunas aplicaciones dal análisis por microsonda electrónica al estudio de los minerales del clínker
} artículo:

En primer lugar el profesor H. Lafuma escribe el siguiente prólogo a este

"La adquisición reciente de una microsonda electrónica de Castaing, por los Laboratorios del Centro de Estudios y de Investigaciones de la Industria de los Conglomerantes Hidráulicos (C.E.R.I.L.H.), permite abordar ciertos problemas todavía insuficientemente resueltos de la química de los cementos. En un primer plano figura el análisis de los minerales del clínker.

Después de haber adquirido un cierto dominio de esta técnica experimental, los físicos del C.E.R.I.L.H. han abordado este problema examinando tres clínkeres industriales. Este primer estudio ha demostrado que si bien el análisis de la alita y de la belita no crea grandes dificultades, el análisis de la fase intersticial parece, por el contrario, muy delicado.

Los esfuerzos de los laboratorios del C.E.R.I.L.H., entre otros, deberán proseguir sobre este punto, dada la insuficiencia de nuestros conocimientos sobre la hidratación de esta fase y de su importancia en el comportamiento del cemento a las aguas agresivas."

\section{INTRODUCCION}

Las cuestiones que se plantean a los investigadores del clínker conciernen, de una parte, a la naturaleza de los minerales formados, y de otra parte, a las propiedades de tales minerales en cuanto a su hidraulicidad. En cuanto a los cristales formados, los llamados alita, belita, fase $\mathrm{AC}_{3}$, fase $\mathrm{AFC}_{4}$, periclasa y cal libre representan aproximaciones que las actuales investigaciones cristalográficas, químicas, fisicoquímicas y microanalíticas tratan de precisar poco a poco. Aquí se presentan los análisis obtenidos por medio de la sonda electrónica de Castaing del C.E.R.I.L.H. para los minerales de tres clínkeres industriales. 
Las primeras imágenes de la repartición de los elementos en los minerales del clínker se obtuvieron por Philibert y Weinryb en un clínker aluminoso (1). Taylor ha presentado en su obra sobre Química del Cemento una imagen electrónica e imágenes por rayos $\mathrm{X}$ para $\mathrm{Ca}, \mathrm{Si}, \mathrm{Al}, \mathrm{Fe}$ y $\mathrm{Ti}$ en un clínker portland (2). Wright (3) ha efectuado determinaciones con microsonda y ha encontrado un exceso de calcio en la alita y un defecto en la belita. Miss Moore (4) ha publicado imágenes por rayos X para $\mathrm{Ca}, \mathrm{Si}, \mathrm{Al}, \mathrm{Fe}$ y $\mathrm{Mg}$ en un clínker con una imagen por electrones retrodifundidos y vía óptica. Ha determinado $\mathrm{Mg}$ en los minerales empleando un testigo de olivino. Los contenidos, expresados en $\mathrm{MgO}$, eran de $1,9 \%$ en la alita, $0,9 \%$ en la belita, $3 \%$ en la ferrita y $13 \%$ en la fase $\mathrm{AC}_{3}$. Terrier y Capitant (5) han examinado cristales de alita en los cuales han encontrado contenidos en $\mathrm{Al}_{2} \mathrm{O}_{3}$ de 0,7 y $1,0 \%$ y en $\mathrm{Fe}_{2} \mathrm{O}_{3}$ de 0,7 y $0,8 \%$. Estos autores indicaron que la relación molecular $\mathrm{CaO} / \mathrm{SiO}_{2}$ de la alita era un poco superior a 3 . Peterson (6) midió en la alita contenidos de alúmina que oscilan de 0,2 a $1,1 \%$ según los clínkeres, pero nada de $\mathrm{K}_{2} \mathrm{O}$. En la belita, los contenidos de $\mathrm{K}_{2} \mathrm{O}$ que ha encontrado son de 0,5-0,8 a $1 \%$. En la fase intersticial ha encontrado hasta $1,7 \%$ de $\mathrm{K}_{2} \mathrm{O}$. El contenido en MgO de la alita varía según los clínkeres; en uno es de 1,2 y en el otro de 1,4 a $2,4 \%$. Del mismo modo, el contenido en $\mathrm{MgO}$ de la fase intersticial fue igual a $0,3 \%$ para un clínker y de $1,8 \%$ para otro.

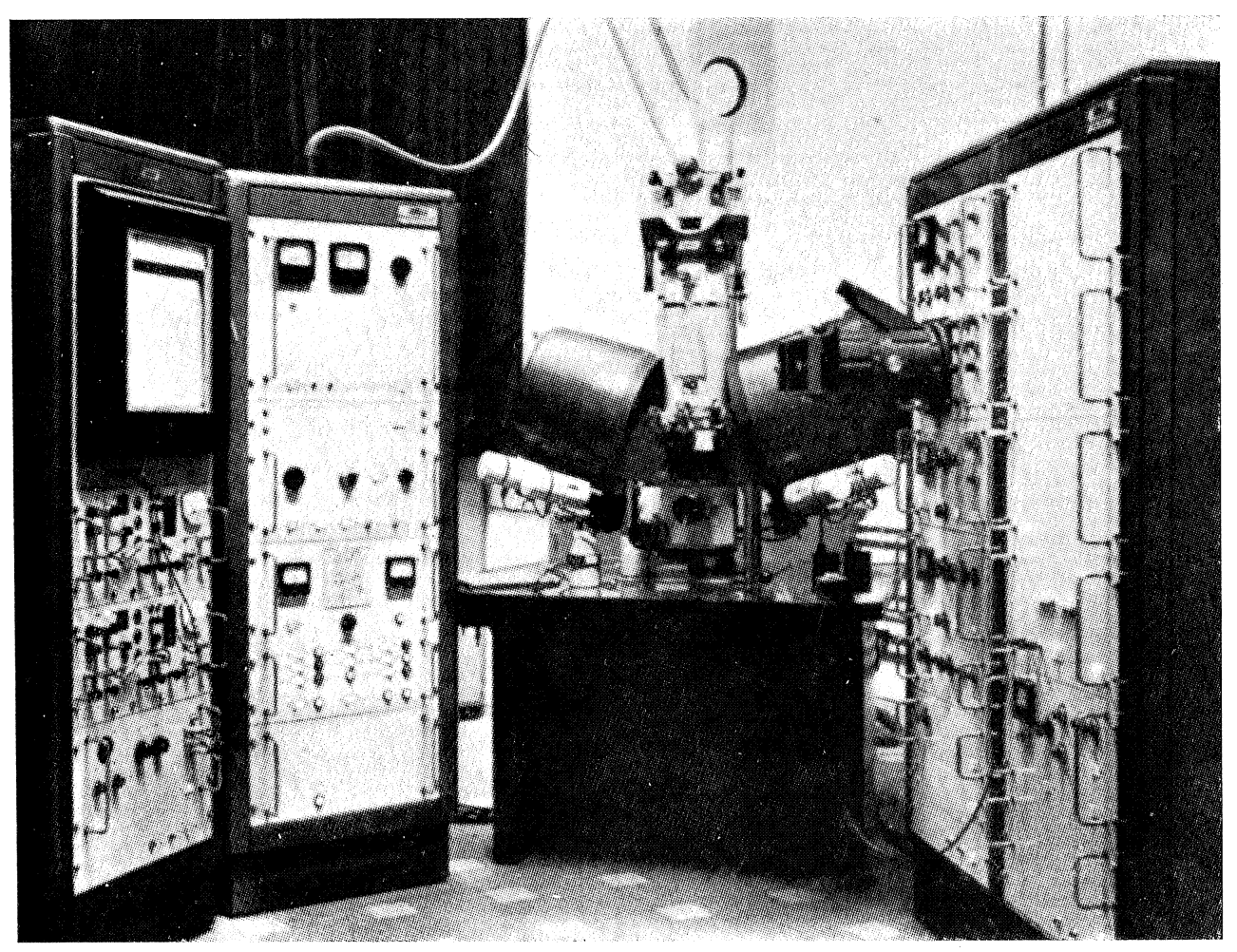

Fig. 1.-Ia microsonda electrónica. 


\section{TECNICA EXPERIMENTAL}

Recordaremos que la microsonda electrónica permite el análisis puntual de una muestra pulida que, bombardeada con vacío bajo el microscopio por un haz de electrones, emite una radiación $\mathrm{X}$ característica de los elementos de que está formada dicha muestra.

\section{1. Optica electrónica}

Un tubo de tipo triodo de autopolarización variable suministra un haz de elecirones de gran intensidad. Dos lentillas magnéticas: un condensador y un objetivo, focalizan el haz electrónico sobre la muestra. Entre el condensador y el objetivo, un conjunto de dos diafragmas asociado a la alimentación electrónica del condensador permite una regulación automática de la intensidad de la sonda. Con las correcciones de astigmatismo y de desplazamiento electrostático, este conjunto de óptica electrónica permite obtener una sonda de un diámetro inferior a $0,5 \mu$ con $30 \mathrm{kV}$.

\section{2. Muestra}

La muestra está constituida por granos de clínker de 0,5-2 mm impregnados en caliente, en un crisol metálico, por una resina Epikote. Una vez endurecida, la preparación se pule con una serie de suspensiones de diamante en aceite, de finura creciente. níquel.

La superficie pulida se hace conductora por depósito bajo vacío de una película de

\section{3. Microanálisis cualitativo y cuantitativo}

La muestra, bajo la acción del bombardeo por el haz de electrones finamente focalizado en su superficie, emite un rayo $\mathrm{X}$ que contiene todas las rayas características de los elementos cuyos umbrales de excitación son inferiores a la tensión aceleradora de los electrones. Cada una de estas rayas se analiza por un espectrómetro de rayos X compuesto de un monocromador y de un detecior móviles sobre un círculo de focalización; el desplazamiento del monocromador y del detector sobre este círculo permite el análisis cualitativo.

La relación de la intensidad emitida por un elemento de la muestra a la que emite en un testigo calibrado, se mide por una posición apropiada del equipo. Permite determinar la concentración del elemento en la muestra. Esto supone una selección de señales que se obtiene por el análisis dispersivo y afinado por una discriminación de energía.

\section{4. Imagen $\mathbf{x}$}

Un dispositivo electrónico o mecánico permite a la sonda explorar una pequeña región en la superficie de la muestra. La señal suministrada por el detector del espectrómetro, después de una amplificación, modificn la intensidad tel hoz electrónico do un osciloscopio. El barrido en $X$ e $Y$ del "spot" está en sincronismo con el haz electrónico de la sonda. Como a cada instante, la intensidad del haz del osciloscopio es proporcional a 
la concentración del elemento analizado en el punto donde se encuentra la sonda, es posible formar sobre la pantalla la imagen de la repartición del elemento considerado en la zona explorada.

\section{5. Imagen electrónica}

Para formar la imagen electrónica se utiliza una señal proporcional al número de electrones absorbidos por la muestra. Esta absorción depende del número atómico medio. Después de la amplificación esta señal modula el haz del osciloscopio.

Un sistema de amplificación de contraste, introducido en la cadena de medida de la corriente absorbida, permite poner en evidencia muy pequeñas diferencias en los números atómicos.

Un inversor de polaridad permite obtener una imagen positiva o negativa. En imagen positiva, las zonas donde la corriente absorbida es débil son brillantes.

\section{RESULTADOS}

Las fotomicrografías de las figuras 2, 3 y 4 representan aspectos característicos de los tres clínkeres industriales estudiados. Las figuras 5 a 13 muestran ejemplos de la repartición, en los minerales de los clínkeres, de los elementos $\mathrm{Si}, \mathrm{Al}, \mathrm{Fe}, \mathrm{Mg}, \mathrm{Ti}, \mathrm{Na} \mathrm{y} \mathrm{K}$, así como las imágenes electrónicas correspondientes. Los gráficos de las figuras 14 a 16, ilustran la puesta en evidencia de algunos elementos en la cal, la fase $\mathrm{AFC}_{4} \mathrm{y}$ la alita. Los resultados de las determinaciones se encuentran en la tabla I. Todos los elementos se han determinado a partir de la radiación $\mathrm{K} \alpha$, por comparación con testigos de la misma naturaleza, sintéticos $\left(\mathrm{C}_{3} \mathrm{~S}, \mathrm{C}_{4} \mathrm{AF}, \mathrm{Al}_{2} \mathrm{O}_{3}\right.$ y $\left.\mathrm{MgO}\right)$ o naturales (ortosa, albita, rutilo, piromorfita y anhidrita).

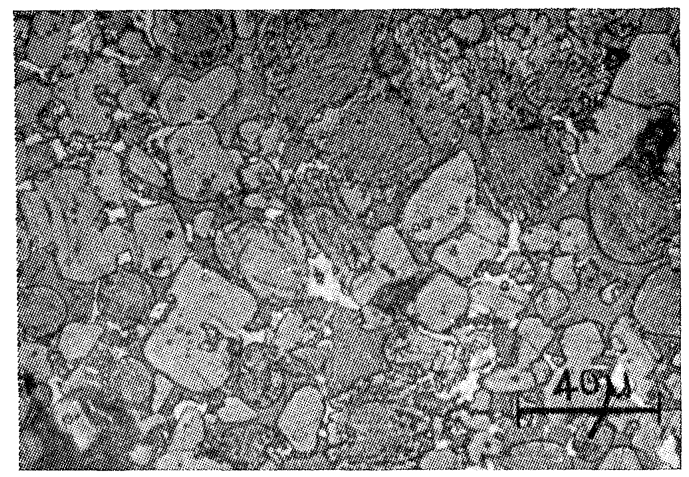

Fig. 2.-Clínker N.o 1 - Vista óptica.

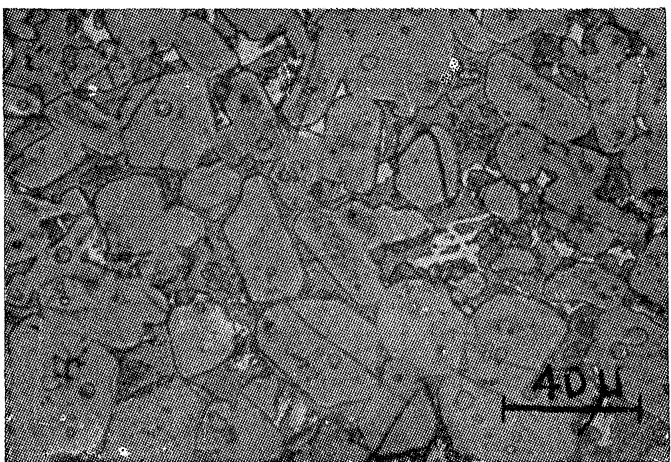

Fig. 3.-Clínker N.o 2-Vista óptica. 


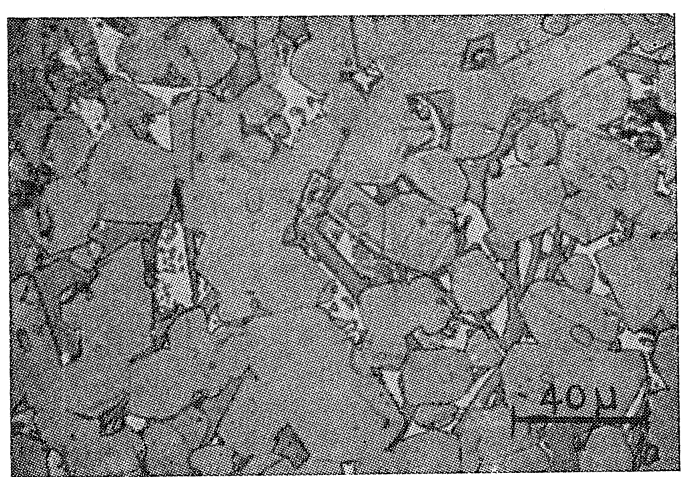

Fig. 4.-Clínker N.o 3 -Vista óptica.

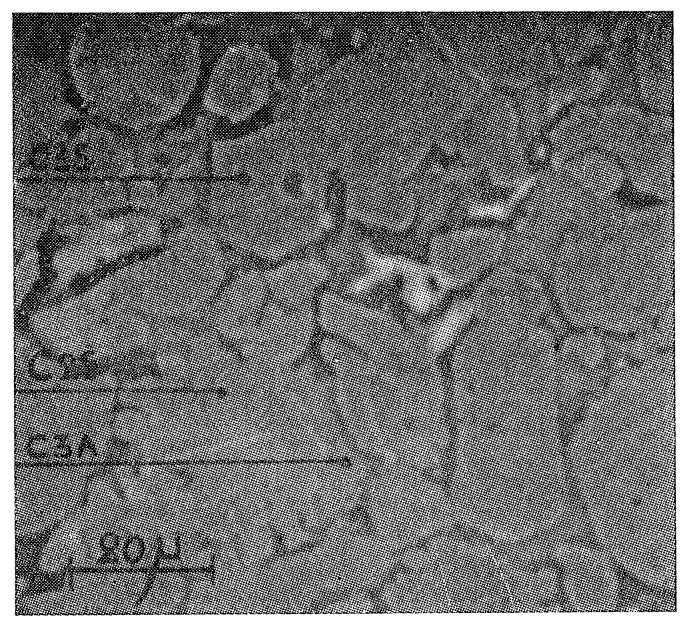

Fig. 5.-Clínker N.o 1 - Imagen electrónica.

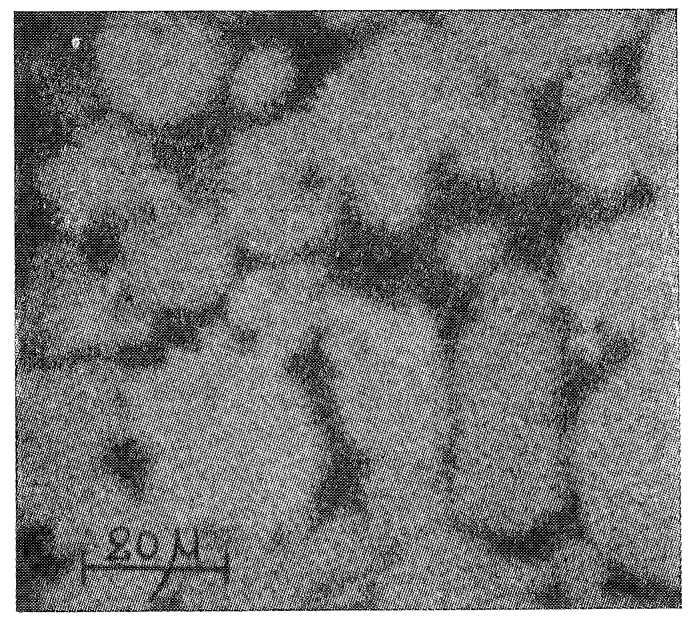

Fig. 6.-Clínker N.o 1 - Imagen $\mathbf{x}$. Repartición del Si

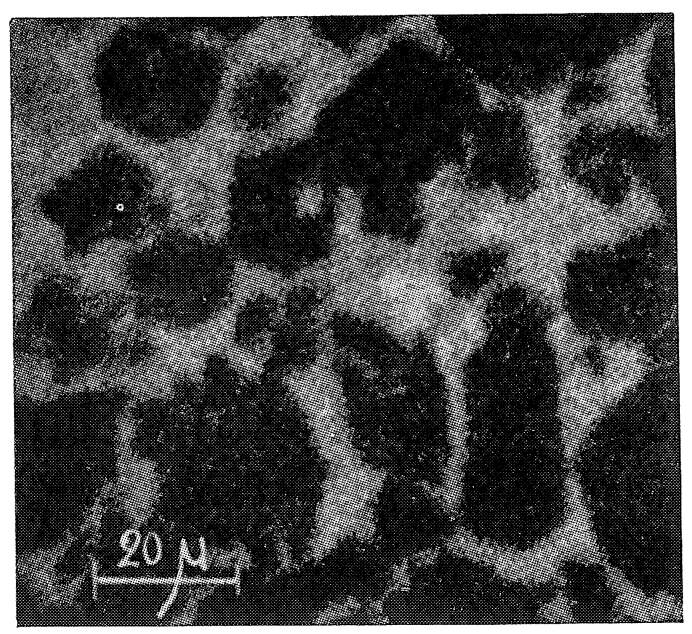

Fig. ‘.-Clínker N.o 1 - Imagen $x$. Repartición de Al.

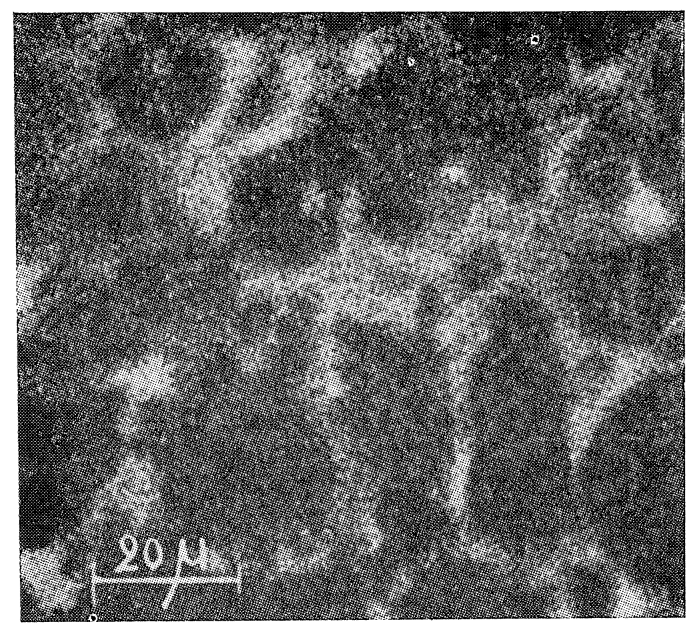

Fig. 8.-Clínker N.o 1 - Imagen $x$. Repartición de Fe.

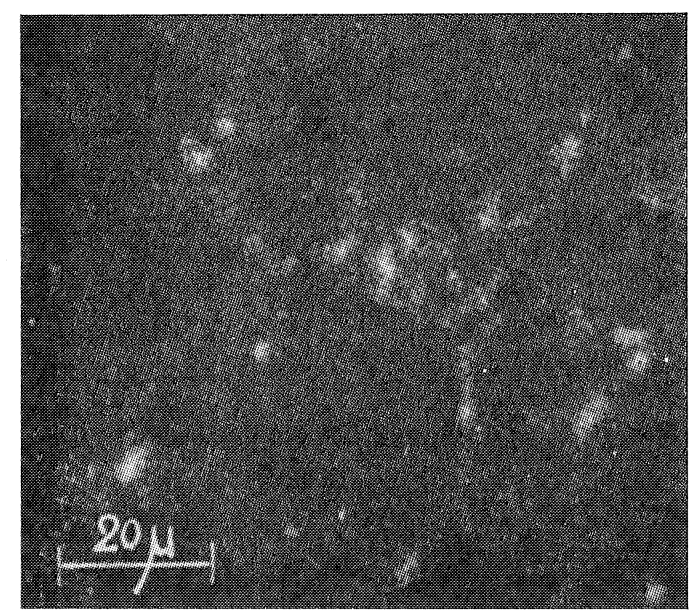

Fig. 9.-Clínker N.o 1-Imagen $\mathrm{X}$. Repartición de Mg. 


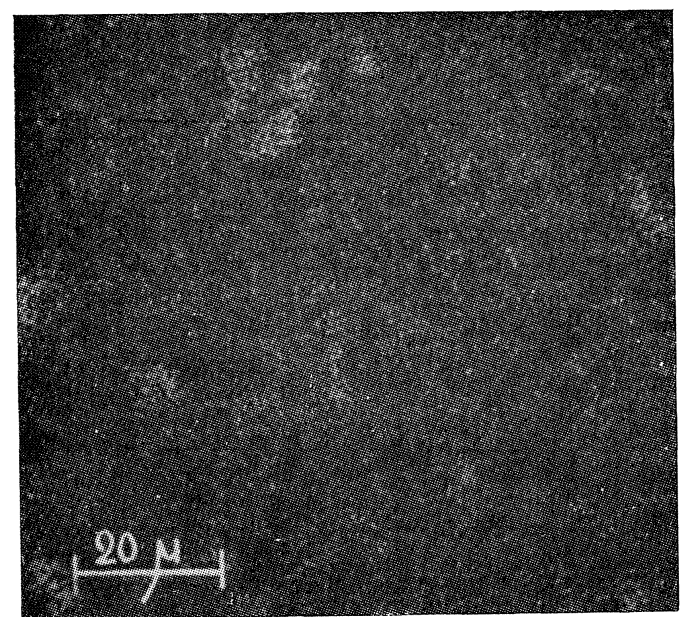

Fig. 10.-Clínker N.o 1 - Imagen $x$. Repartición de Ti.

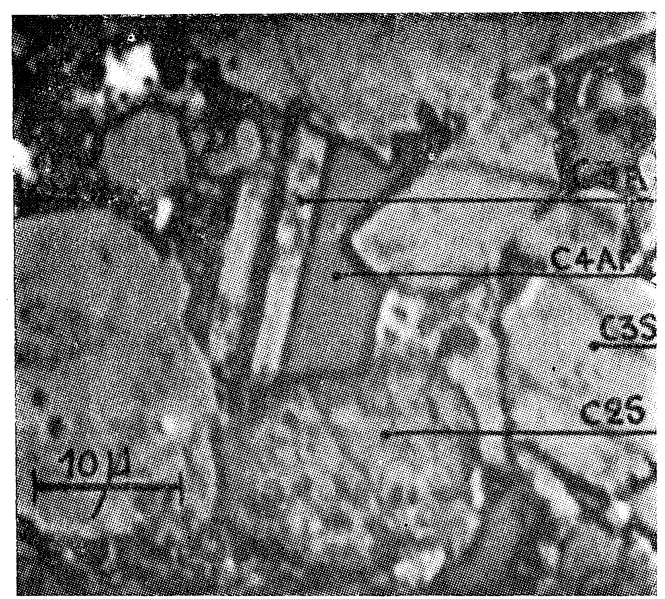

Fig. 11.-Clínker N.o 3-Imagen electrónica.

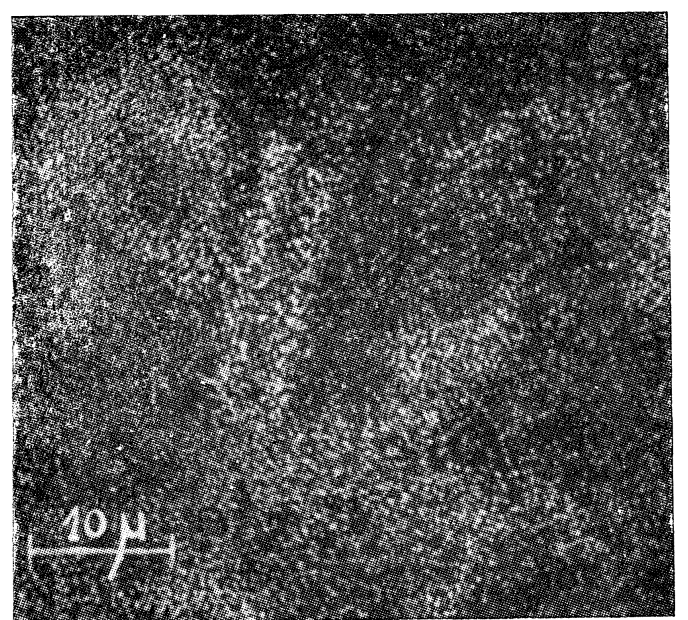

Fig. 12.-Clínker N.o 3 - Imagen $x$. Repartición de $k$.

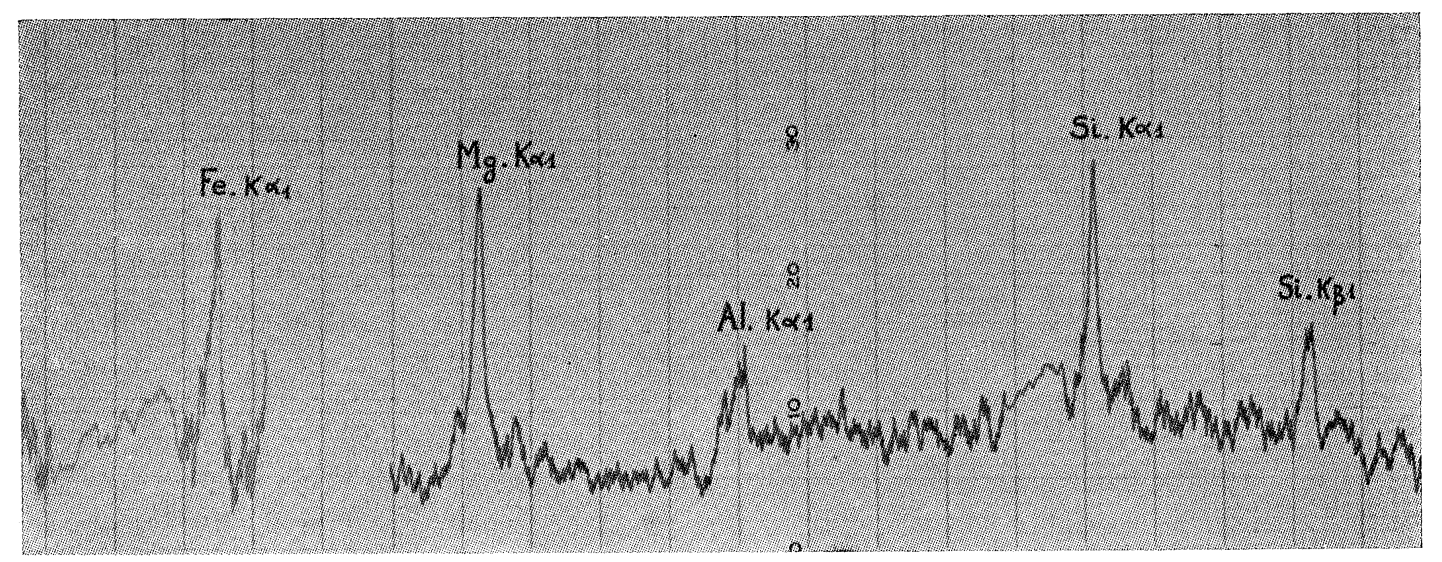

Fig. 14.-Clínker N.o 2 - Espectro de la cal libre. Cristales analizadores: Cuarzo 1011 y KAP. 


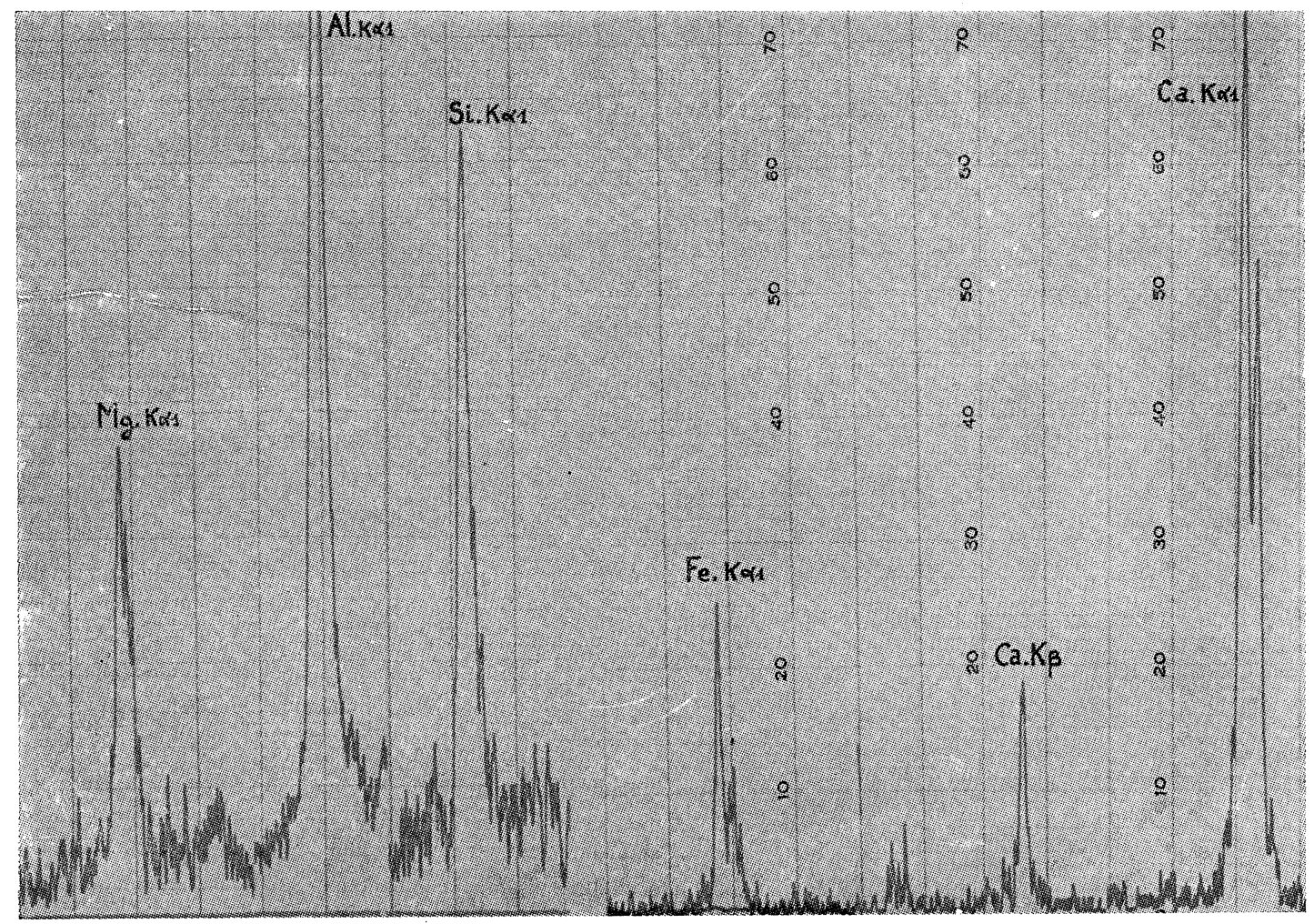

Fig. 15.-Clínker N.o 2 -Espectro de la fase $C_{4} A F$. Cristal analizador: KAP Cristal analizador: cuarzo 1010.

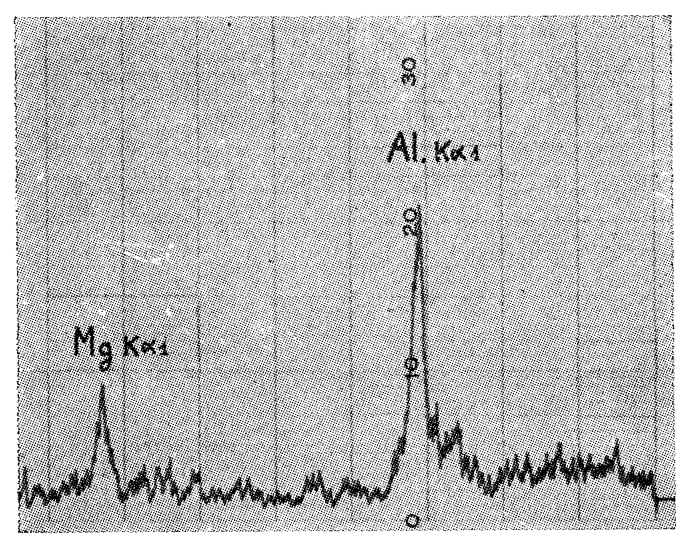

Fig. 16.-Clínker N.o 2 -Intensidad relativa de $M g k \alpha$ y Al $\mathrm{K} \alpha$ en un cristal de alita.

\section{DISCUSION}

\section{Alita}

La alita de los clínkeres encierra alrededor de un $3 \%$ de óxidos menores y un exceso de cal con relación a la sílice: relación molecular $\mathrm{CaO} / \mathrm{SiO}_{2}$ un poco superior a 3 . Los principales óxidos menores son: $\mathrm{Al}_{2} \mathrm{O}_{3}, \mathrm{Fe}_{2} \mathrm{O}_{3}$ y $\mathrm{MgO}$ cuyo contenido en la alita varía de un clínker a otro. 


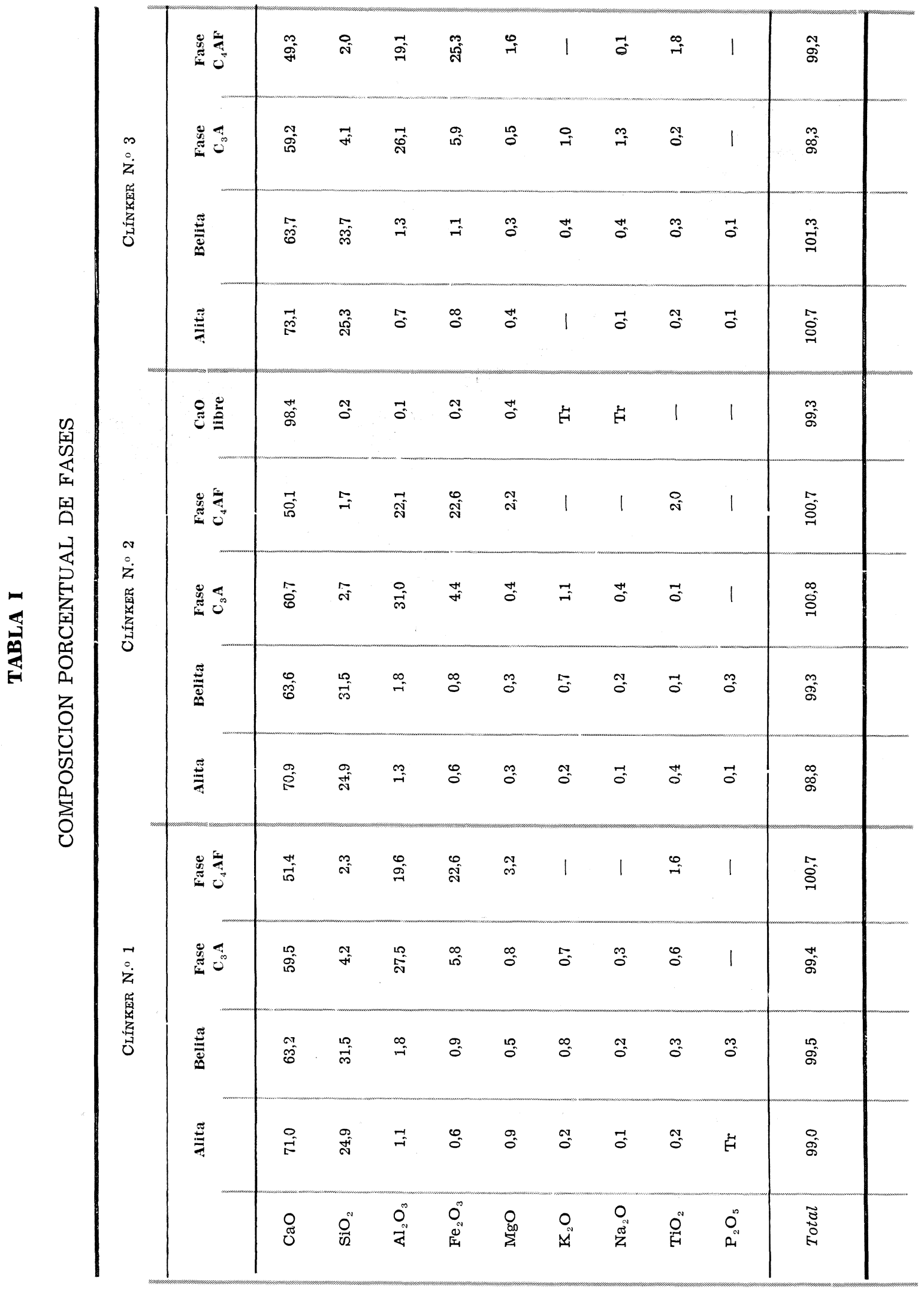




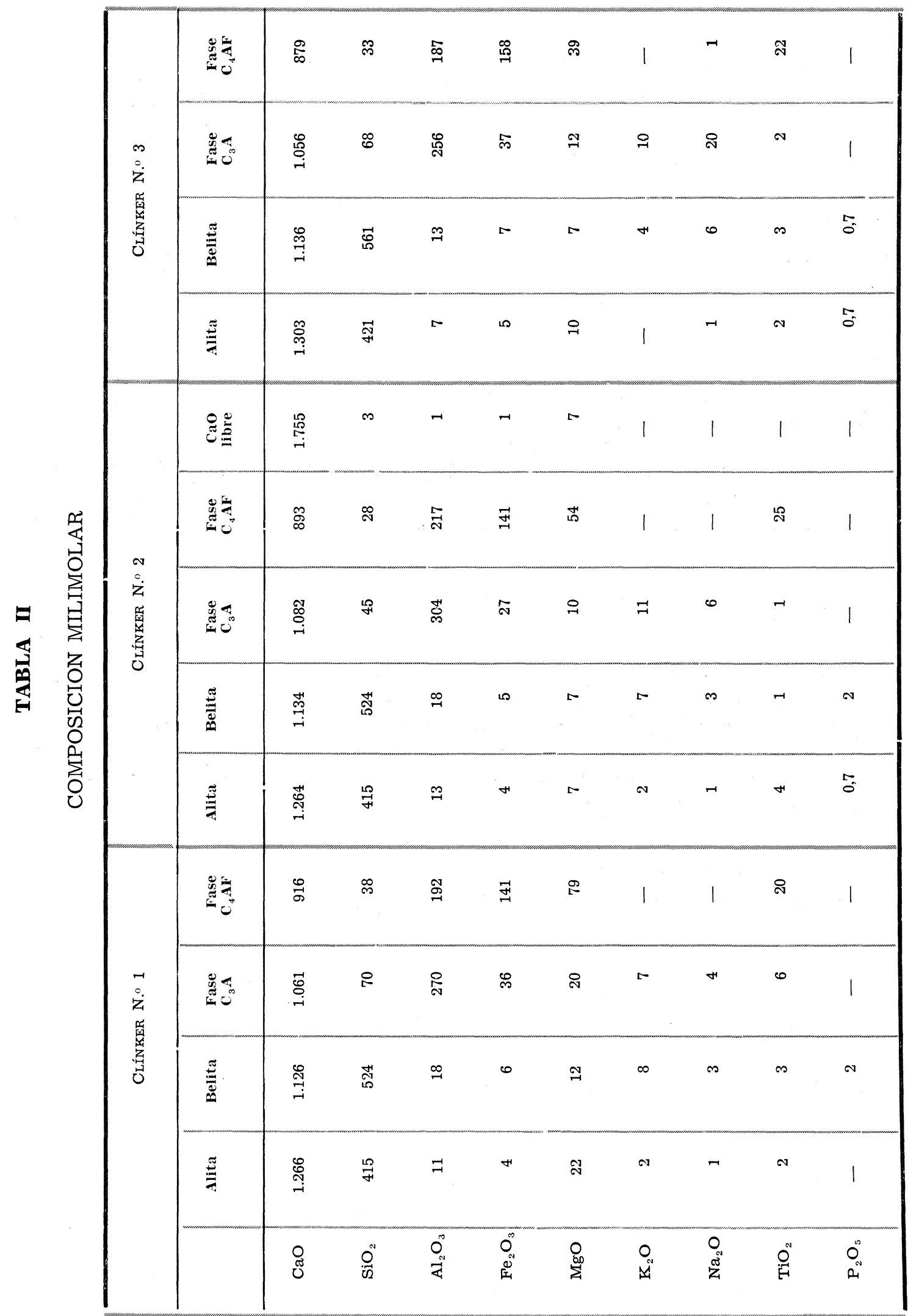




\section{Belita}

La belita encierra hasta $5 \%$ de óxidos menores. Los contenidos en magnesia son del mismo orden que los de alita. Los contenidos en $\mathrm{Al}_{2} \mathrm{O}_{3}, \mathrm{Fe}_{2} \mathrm{O}_{3}, \mathrm{~K}_{2} \mathrm{O}$ y $\mathrm{Na}_{2} \mathrm{O}$ son superiores a los de la alita. La relación molecular $\mathrm{CaO} / \mathrm{SiO}_{2}$ de la belita es un poco superior a 2 .

\section{Cal libre}

El análisis demuestra que la cal libre encierra también pequeñas cantidades de óxidos minerales.

\section{$\mathbf{C}_{3} \mathbf{A}$ y $\mathbf{C}_{4} \mathbf{A F}$}

Las determinaciones con la microsonda proporcionan contenidos en $\mathrm{CaO}, \mathrm{Al}_{2} \mathrm{O}_{3}$ y $\mathrm{Fe}_{2} \mathrm{O}_{3}$ diferentes de los valores teóricos para las fases $\mathrm{C}_{3} \mathrm{~A}$ y $\mathrm{C}_{4} \mathrm{AF}$, las cuales encierran contenidos relativamente importantes de óxidos menores que consisten: para el $\mathrm{C}_{3} \mathrm{~A}$, en $\mathrm{SiO}_{2}, \mathrm{Fe}_{2} \mathrm{O}_{3}$ y $\mathrm{MgO}$, y para el $\mathrm{C}_{4} \mathrm{AF}$ en $\mathrm{MgO}$ y $\mathrm{SiO}_{2}$. El $\mathrm{TiO}_{2}$ se fija sobre todo en el $\mathrm{C}_{4} \mathrm{AF}$, mientras que los álcalis se fijan más bien en $\mathrm{C}_{3} \mathrm{~A}$. Es preciso señalar a propósito de los álcalis que los dos óxidos, $\mathrm{Na}_{2} \mathrm{O}$ y $\mathrm{K}_{2} \mathrm{O}$, se encuentran relacionados uno con el otro.

\section{CONCLUSION}

Los análisis con la microsonda proporcionan para tres clínkeres industriales, los contenidos medios en $\mathrm{CaO}, \mathrm{SiO}_{2}, \mathrm{Al}_{2} \mathrm{O}_{3}, \mathrm{Fe}_{2} \mathrm{O}_{3}, \mathrm{MgO}, \mathrm{K}_{2} \mathrm{O}, \mathrm{Na}_{2} \mathrm{O}, \mathrm{TiO}_{2}$ y $\mathrm{P}_{2} \mathrm{O}_{5}$, de la alita, de la belita, de la fase $\mathrm{C}_{3} \mathrm{~A}$, de la fase $\mathrm{C}_{4} \mathrm{AF}$ y, para uno de ellos, la cal libre. Se encuentra en estudio la localización de los elementos $\mathrm{Cr}$, Mn, S y Co. Es preciso señalar que pueden existir de un cristal a otro variaciones importantes de composición, por ejemplo variaciones de $\mathrm{P}_{2} \mathrm{O}_{5}$ en la belita.

En lo que concierne a la fase intersticial, el enredo de los aluminatos y la presencia de inclusiones (periclasa, belita, etc.) hacen delicadas las determinaciones, y los resultados de este estudio exigen completarse o afinarse.

\section{BIBLIOGRAFIA}

(1) Philibert, J. y WeInryp. E.: Quelques applications du balayage automatique sur la microsonde de Castaing, 1962. Journal de Microscopie, vol. 1, núm. 1, 13-22.

(2) TAYloR, H. F. N.: The Chemistry of cements. 1964 Academic Press, London y New York, vol. 1-119-120.

(3) WRIght, P. W.: Rapport no publicado, citado por Taylor.

(4) Moore, A. E.: Examen d'un clinker de ciment portland par microanalyse à la sonde électronique. 1965. Silicates Industriels, Belg. XXX, núm. 8-445-50.

(5) Terrier, P. y CAPITANT, M.: Etude de l'hydratation du ciment portland par microanalyse (émission $X$ ), 1965 - IV Congrès Intern. Optique des Rayons X et Microanalyse-Orsay-Hermann, éd. Paris.

(6) Peterson, O.: Untersuchung von Portland-Klinker mit der Mikrosonde, 1967 -Zement Kalk Gips número $2-61-4$ 